\title{
Distal radyoulnar eklemde hemirezeksiyon interpozisyon artroplasti uygulamaları
}

\section{Hemiresection interposition arthroplasty procedures on the distal radioulnar joint}

\author{
Okyar Altaş ${ }^{1}$, Ömer Ayık², Hayati Durmaz \\ ${ }^{1}$ İstanbul Üniversitesi İstanbul Tıp Fakültesi, El Cerrahisi Bilim Dalı, İstanbul, Türkiye \\ ${ }^{2}$ Atatürk Üniversitesi Ortopedi ve Travmatoloji Ana Bilim Dalı, Erzurum, Türkiye \\ ${ }^{3}$ Istanbul Üniversitesi İstanbul Tıp Fakültesi, Ortopedi ve Travmatoloji Ana Bilim Dalı, İstanbul, Türkiye
}

\begin{abstract}
El bileği eklemi çevresi problemleri; geçmişten günümüze kadar ortopedi ve el cerrahisi polikliniklerine başvuran hastaların önemli bir bölümünü oluşturmaktadır. Geçmişte distal radyoulnar eklemle ilgili yapılan radikal girişimler, yerini zamanla daha az morbiditesi olan ve yumuşak doku dengesinin korunarak yapıldığı işlemlere bırakmıştır. Bu anlamda uygun hastalarda hemirezeksiyon interpozisyon artroplastisi, oldukça başarılı bir yöntem olarak karşımıza çıkmaktadır. Bu yazıda, hemirezeksiyon interpozisyon artroplasti tekniğinin gelişiminin tarihçesinden başlayarak cerrahi yönteminin tanımına, işlemin potansiyel komplikasyonlarının yönetimine ve sonuçları üzerine odaklanılmış, bu anlamda kendi uyguladığımız yönteme de yer verilmiştir.

Anahtar sözcükler: distal radyoulnar eklem, instabilite, artroz, interpozisyonel artroplasti
\end{abstract}

\begin{abstract}
Wrist problems; a delicacy in the disease that has applied to Orthopaedics and Hand Surgery clinics from past to present. In the past, radical interventions related to the distal radioulnar joint have been replaced by procedures with less morbidity and preserving soft tissue balance. It emerges as such a successful method. In this article, we focus on the description of the method, overcoming the possibilities and its consequences, starting from the history of the development of hemiresection arthroplasty technique, and this method that we have applied is also included.
\end{abstract}

Key words: distal radioulnar joint; instability; arthrosis; interpositional arthroplasty

\section{TARIHÇE}

Distal ulna rezeksiyonu; 1880'de Moore tarafindan tanımlanmış ve 1912 'de Darrach tarafindan popülarize edilmiştir. ${ }^{[1-3]}$ Erken sonuçlarının yüz güldürücü olmasına karşın geç dönemde gelişen problemler (ulnoradyal sıkışma 'impingement', dorsal ulnar subluksasyon, tendon rüptürleri, snapping ulna vb.) nedeniyle alternatif yöntemler düşünülmeye başlanmıştır. ${ }^{[4,5]}$ Distal radyoulnar eklemde (DRUE) uygulanan hemirezeksiyon interpozisyon artroplasti (HiA); 1978'de ilk kez uygulanmış, literatürde ilk kez 1985 yılında Bowers tarafından tanımlanmış olup günümüzde farklı modifikasyonlarla kullanılmaya devam eden bir teknik olarak karşımıza çıkmaktadır. ${ }^{[6]}$ Bowers'ın geliştirdiği HïA ve Watson'un geliştirdiği eşleştirilmiş - uyumlu

hale getirilmiş (matched) distal ulna rezeksiyonlarında ana prensip; ulnanın DRUE'ye bakan yüzündeki kıkırdak ve subkondral kemiğin çıkarılması ile ulnar stiloid ve triangular fibrokartilaj kompleksi (TFKK) yapışma yerlerinin korunması olarak bahsedilmiş ve başarılı sonuçlar yayımlanmıştır. ${ }^{[7]}$ Bu çalışmaları takiben; DRUE üzerindeki cerrahi çekinceler azalmış ve patomekanik daha iyi anlaşılmaya başlanmıştır. Minami ve ark. ile diğer yazarlar peş peşe başarılı sonuçlarını 1980'lerin sonunda yayımlamaya başlamışlardır. ${ }^{[8]}$

Günümüzde HİA endikasyonlarına bakıldığında; travma (ulna başının rekonstrüksiyonuna izin vermeyen ileri derecedeki parçalı kırıkları), romatoid artrite bağlı DRUE sorunları, ulnokarpal impingement sendromu (özellikle yetersiz DRUE yüzüne sahip distal

- İletişim adresi: Okyar Altaş, İstanbul Üniversitesi İstanbul Tıp Fakültesi, El Cerrahisi Bilim Dalı, İstanbul, Türkiye Tel: 0531 - 6665630 e-posta: okyaraltas@gmail.com

- Gelis tarihi: 25 Mayıs 2021 Kabul tarihi: 2 Haziran 2021

ORCID iD: Okyar Altaş, 0000-0002-1262-6073 • Ömer Ayık, 0000-0002-3437-6394 • Hayati Durmaz, 0000-0002-2571-6617 
radius kırı̆̆ı yanlış kaynamalarına sekonder); travma sonrası DRUE artriti ve artrozu, osteoartrit, kronik (ancak onarılabilir) ve semptomatik TFKK yırtıklarına eşlik eden DRUE'nin ağrılı instabilitesi ve ulna başı kondromalazisi olarak özetlenebilir.

Kontrendikasyonları ise; fonksiyonel olarak yeterli (örneğin santral yırtıklar) veya rekonstrükte edilebilir TFKK bütünlüğünün olmayışıdır. Fonksiyonel TFKK yoksa; HiA tekniğinin Darrach (ulna başı total rezeksiyonu) prosedürüne bir üstünlüğü yoktur. Triangular fibrokartilaj kompleksinin bütünlüğünün değerlendirilmesinde manyetik rezonans (MR) artrografi kullanılabilir.

Triangular fibrokartilaj kompleksinin fonksiyonları; triangular fibrokartilaj sayesinde rotasyona izin veren stabil DRUE devamlılığı, ulnokarpal ligamentöz kompleksi sayesinde elde edilen stabil ulnokarpal bağlantı, ulnadan el-el bileğine yük aktarımı, triangular fibrokartilaj ve ulnokarpal ligamentlerin ulnar karpal bölgenin radiusa askı şeklinde asılmasının sağlanması ve proksimal karpal sıra kemiklerinin ön kol distal kemikleri (ulna ve radius) üzerinde kayma etkisinin sağlanması olarak özetlenebilir.

\section{CERRAHI TEKNIK}

Ön kol pronasyonda iken; tepesi ulnar stiloide gelecek şekilde DRUE'ye göre proksimalde $5 \mathrm{~cm}$ distalde $3 \mathrm{~cm}$ 'lik Brunner insizyonu takiben cilt ve cilt altı dokular kaldırılır. Ekstansör retinakulum ve ulnar sinirin dorsal duyusal dalı bulunur. Sinir ameliyat süresinde korunmalıdır. Ekstansör dijiti minimi (EDM) ulna başı proksimalinin radyal tarafında yer alırken ekstansör karpi ulnaris (EKU) tendonu ulna başı proksimalinin ulnarinde yer alır. El bileği seviyesinde DRUE kapsülü bu iki tendon arasında yer almaktadır. EDM tendonu 5. ekstansör kompartmandan longitudinal eksende parsiyel olarak serbestlenir. Ekstansör karpi ulnaris tendonunun dorsal stabilizasyonu gerekliyse ve/veya triangular fibrokıkırdakta defekt mevcutsa; onarım için proksimal-ulnar bazlı retinaküler flep (proksimal 2/3) oluşturulur. Distal 1/3 retinaküler flep ise; DRUE rekonstrüksiyonu için saklanır. Ekstansör karpi ulnaris kapsülü, ulna başına yapışma bölgesinde korunur. Triangular fibrokıkırdakta hasar yoksa, DRUE kapsülü sigmoid çentiğin (sigmoid notch'un) dorsalinde transvers olarak ayrilarak ulnar bölgeye doğru katlanır.

Bu aşamada ulna başı yeterince ekspozedir ve rezeksiyon için hazır hale gelir. Ulna distal şaft ve stiloidi ile TFKK korunacak şekilde; ulnanın distal radyoulnar eklemle ilişkili artiküler yüzü ve subkondral kemik eksizyonu yapilır. Bu sayede ulnokarpal ve radyoulnar bağlantılar da korunur ve ulnar kolon instabilitesi riski ortadan kalkar. Ulnar stiloid ve TFKK'nin korunması,
HiA operasyonunun mihenk taşıdır. Hangi endikasyon olursa olsun, HiA'ya karar verildiğinde bu iki prensip asla unutulmamalıdır. ${ }^{[9]}$

Bowers'ın tarif ettiği şekilde; testere veya osteotom eşliğinde osteotomi tamamlanır. Ulna başının volar köşesinin tam rezeksiyonu zor olabilir, bu aşamada kemik doku ayırıcı (lamina spreader gibi) kullanılabilir. ${ }^{[6]}$ Uyumlu bir rezeksiyon yüzeyi için ulna başından $3 \mathrm{~cm}$ proksimale kadar subperiosteal disseksiyon gerekliliği de hatırda tutulmalıdır.

Ulna distal uçta eksizyon yapıldıktan sonra TFKK belirgin olarak görülür. TFKK'de görülen santral yırtıklar veya perforasyonlar fonksiyonel olarak problem yaratmamaktadır. Bu nedenle tamir de gerektirmez. Periferik marjinde görülen ayrışmalar ve yırtıklar (romatoid artritte çok sıktır), tamir için uygundur. TFKK'de periferik/marjinal onarıma uygun bir yırtık görülürse ikincil adı verilen distal retinaküler flep ya da EKU/fleksör karpi ulnaris (FKU) distal bazlı strip'leri ile onarım yapılabilir.

Ulna başı; TFKK ve stiloide zarar vermeksizin eksize edildikten sonra radius ve ulnaya aksiyel kompresyon ve ulnar deviasyon uygulanarak radyo-ulnar ve stilokarpal sıkışma veya daralma olmadığı kontrol edilmelidir. Sıkışmadan ya da daralmadan şüphe edilirse, ulnar kısaltma osteotomisi ya da boşluğun palmaris longus $(\mathrm{PL})$ tendonu ile interpozisyonu da düşünülmelidir. Palmaris longus tendonu alındığında top haline getirilerek volar kapsüle emilmeyen dikişlerle tespit edilmeli ve stabilite kontrolü tekrar yapılmalıdır. Kanama kontrolünü takiben dorsal kapsül onarımı yapılarak cilt insizyonu kapatılır.

Çoğu olguda interpozisyonel materyal olarak ulnar bazıı kapsüler flep kullanılmaktadır. Ancak, pozitif ulnar varyans varlığında ya da stiloid normale göre fazla uzunsa ulnar stiloid ile karpal kemikler arasında sıkışma meydana gelir (Stilo-karpal impingement). Bu hastalar ameliyat sonrası ağrı ile karşımıza gelmektedir. Bu problemin en iyi çözümü iyi bir ameliyat öncesi değerlendirmeden geçmektedir. Eğer pozitif ulnar varyans $2 \mathrm{~mm}$ 'den büyükse, HiA ile birlikte ulnar kısaltma yapılmalıdır. Pozitif ulnar varyans $0-2 \mathrm{~mm}$ arasında ise ya da stiloid normale göre fazla uzunsa ulnar kısaltmaya gerek olmaz; interpozisyon materyali olarak kapsüler flepten daha kalın bir boşluk doldurucu bu sorunu çözmek için yeterlidir.

Palmaris longus, EKU, FKU tendonları önerilen boşluk dolduruculardır. Bu tendonlar alınarak top şeklinde bir şekil oluşturulup DRUE'ye yerleştirilir, palmar ve dorsal kapsüle dikilerek olduğu yere sabitlenir. Bunun yanı sıra, pronator kuadratus kasının ulnar yapışma yerinden periost ile birlikte kaldırılarak 


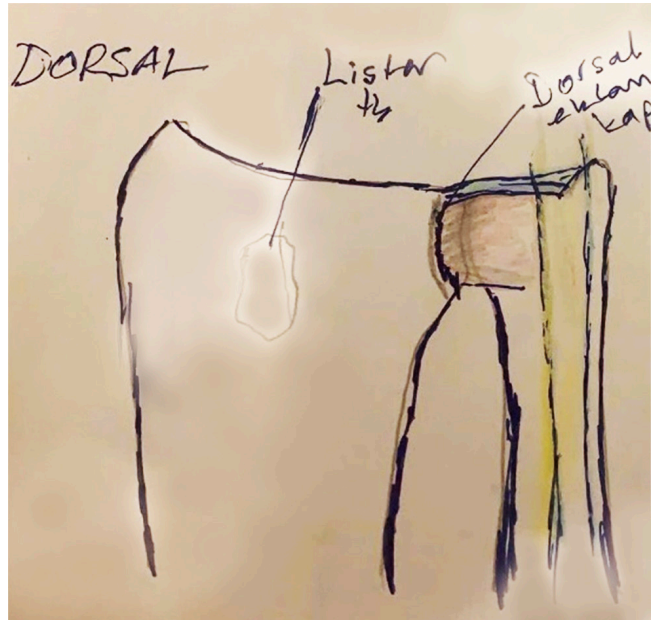

Şekil 1. Dorsal insizyonu takiben distal retinaküler flep ve dorsal eklem kapsülü oluşturulur.

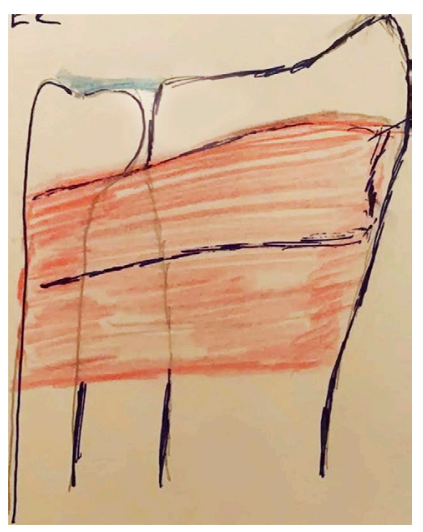

Şekil 2. Volar insizyonla girilerek pronator kuadratusun radial yapışma bölgesinin distal yarısı "L" insizyon ile radiustan periostu ile birlikte kaldırılır.

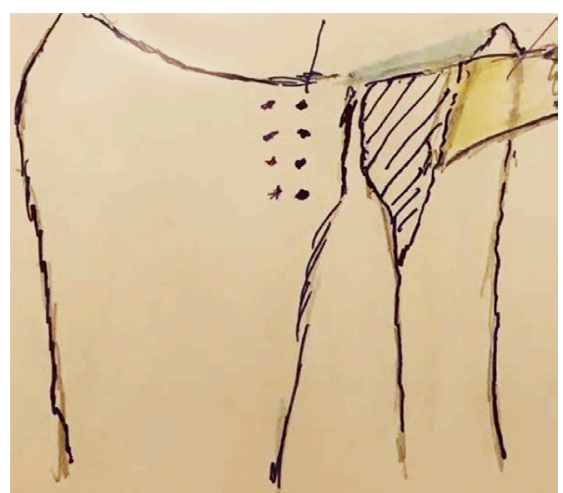

Şekil 3. Bowers'ın tariflediği şekilde, triangular fibrokartilaj komplekse (TFFK) ve ulnar stiloide zarar vermeden, ulnar distal oblik ostektomi yapılır. TFKK bu aşamada değerlendirilir. Gerekirse onarılır. Takiben radius distal dorsale delikler açılarak pronator kuadratus, retinaküler flep ve dorsal eklem kapsülünün taşınacağı yer oluşturulur.

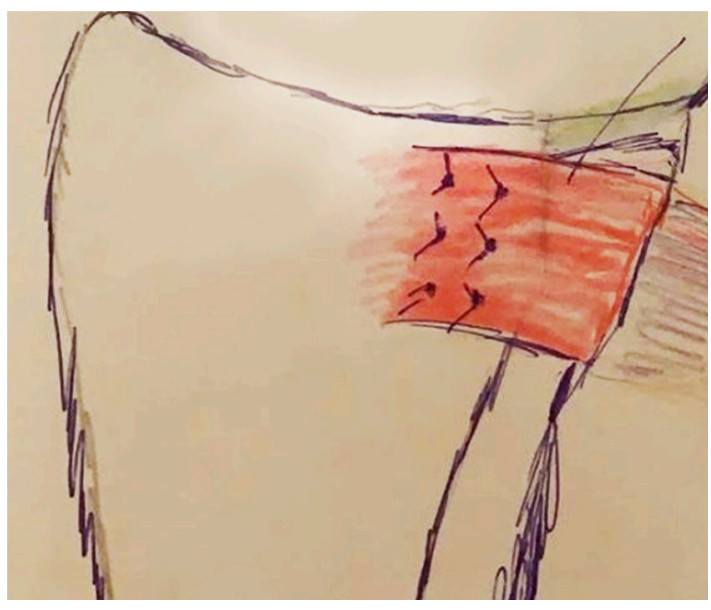

Şekil 4. Distal retinaküler flep, dorsal eklem kapsülü ve pronator kuadratusun distal yarısını volarden dorsale geçirerek radius dorsal ve distaline çift sıra tamir şeklinde taşınması.

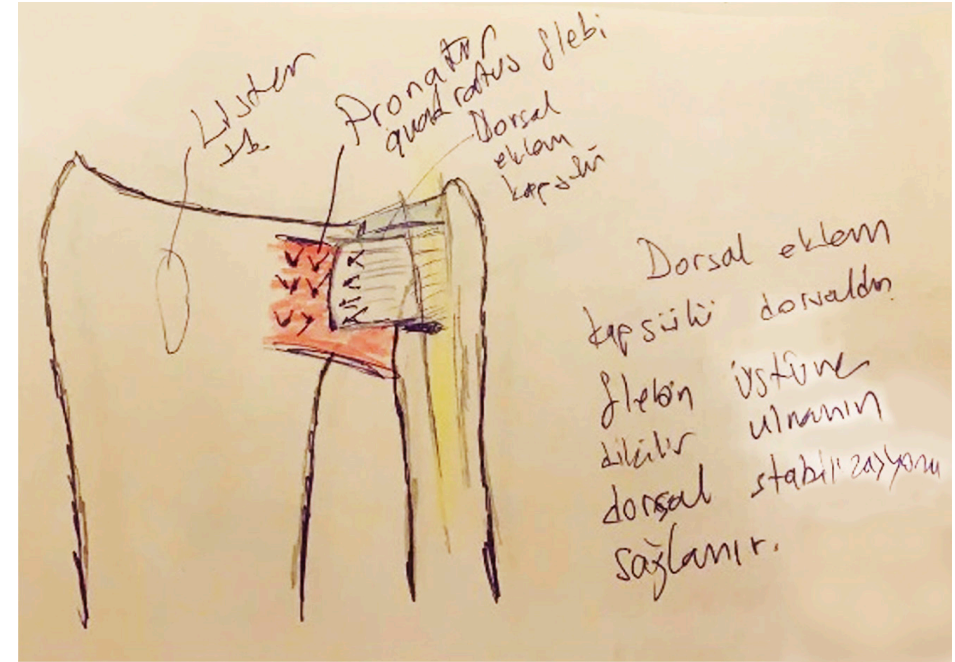

Şekil 5. Onarım ve transferler tamamlandıktan sonraki son görüntü. dorsale taşınması ve DRUE'yi dolduracak şekilde interpozisyon uygulanmasını da içeren teknikler de kullanılmaktadır. ${ }^{[10]}$

Biz klinikte kendi uygulamamızda, dorsal eklem kapsülü ve distal retinaküler flebe ilâveten (Şekil 1) pronator kuadratus kasının volar ve radyaldeki yapışma yerininin distal yarısını periostu ile birlikte kaldırarak (Şekil 2), ulna kemik rezeksiyonu yapıyoruz ve radius distal dorsale iki sıra delikler açıyoruz (Şekil 3). Triangular fibrokartilaj kompleksinde onarım gerektiren bir patoloji varsa EKU'dan aldığımız bir strip ile onarımını gerçekleştiriyoruz. Distal retinaküler flep, dorsal eklem kapsülü ve pronator kuadratusun distal yarısını volarden dorsale geçirerek radius dorsal ve distaline çift sıra şeklinde taşıyoruz (Şekil 4). Bu sayede DRUE'de nitelikli bir hacim oluştuğuna inanıyoruz ve distal radyoulnar instabilite ile karşılaşma olasılığının diğer yöntemlere göre daha az olduğunu düşünüyoruz (Şekil 5).

\section{AMELIYAT SONRASI TEDAVI}

Pasif rehabilitasyon ve atellemeyi (splintlemeyi) takiben eklem hareket açıklığı (EHA) egzersizleri ve güçlendirme sırasıyla uygulanır. Splintleme, kapsüler tamiri korumak amacıyla ön kol rotasyonlarına engel olacak şekilde yapılır. Splint içerisinde parmak hareketlerine izin verilir ancak elin bir şeyi kuvvetli sıkmasına (power grip) izin verilmemelidir. Aktif ve pasif el bileği 
hareketleri (fleksiyon, ekstansiyon, pronasyon ve supinasyon) 6 . haftada, güçlendirme egzersizleri ise 8 . haftada başlanır. Triangular fibrokartilaj kompleksi onarımı yapılmışsa bu sürelere 1-2 hafta daha eklenmelidir.

\section{TEKNIK HATALAR}

Karşımıza ilk olarak yetersiz kemik eksizyonu çıkmaktadır. Bunun yanı sıra DRUE'yi ilgilendiren geniş osteofitler de bu eksizyona mutlaka dâhil edilmelidir. $\mathrm{HIA}$ ameliyatı bitiminde rotasyon kontrol edilmeli ve herhangi bir sıkışma olmadığına emin olunmalıdır. Radius ve ulna birbirine yaklaştırılıp ulnar deviasyon yapılarak stilo-karpal impingement olmadığına emin olunmalı; eğer varsa ulnar kısaltma ve interpozisyonel materyalin kalınlaştırılması gibi ek girişimler ile kombine edilmelidir. Eğer rezeksiyon fazla yapılırsa ulna proksimalinde de kırıklar oluşabilir. Bu durumda kırık tedavisi (plak-vida vb.) uygulanır.

Hemirezeksiyon interpozisyon artroplastiden yarar görmeyen hastalarda dinamik ulnar sıkışma (impingement) veya radyoulnar konverjansa bağlı olarak DRUE'de anormal kontakt basınçların meydana geldiği biyomekanik çalışmalar ile gösterilmiştir. ${ }^{[11]}$ Bu hastalarda, González del Pino ve Fernández'in geliştirdiği modifiye Sauvé-Kapandji yöntemi ile başarılı sonuçlar almak mümkündür. Bu teknikte, Sauvé -Kapandji prosedüründe uygulanan standart teknik ile ulnadan yaklaşık $1 \mathrm{~cm}$ olarak çıkarılan segment, DRUE'ye adapte edilir, FKU tendonu ile tenodez sağlanarak füzyon gerçekleşir. ${ }^{[12]}$

Normal bireylerde dahi, DRUE'nin fizyolojik rotasyon derecelerinde tam uyumlu (congruent) bir eklem olmadığı unutulmamalıdır. Farklı rotasyon derecelerinde sigmoid çentik ve ulna başı farklı uyum (suzluk) lara sahiptir. DRUE'nin cerrahi öncesi değerlendirmesinin doğru şekilde yapılması için günümüz şartlarında dinamik bilgisayarlı tomografi (4D-CT) oldukça net bilgiler sağlamaktadır. Bu sağlanamadığı takdirde; ön kolun farklı rotasyonlarında (pronasyon-supinasyon ve ara dereceler) bilgisayarlı tomografi ya da röntgen incelemeleri ile daha net sonuçlara ulaşmak mümkündür.

Sonuçlara bakıldığında, doğru endikasyon ile yapılan Hï'nın ağrının azalması ve eklem hareket açıklığının artması yönünde oldukça yararlı olduğu gösterilmiştir. ${ }^{[6,7]}$ Distal radyoulnar eklem osteoartritinde uygulanan üç farklı tedavinin (Darrach, Sauvé-Kapandji, HiA) uzun dönem sonuçlarını karşılaştıran bir çalışmada, HIA'nın Darrach prosedürüne göre, cerrahi sonrası sıkma gücü (grip strength), komplikasyonlar ve el bileği instabilitesinin giderilebilmesi açısından daha başarılı olduğu gösterilmiştir. ${ }^{[13]}$ Van Schoonhoven ve ark., orijinal Bower's tekniğini önermelerine rağmen, HiA işlemi gerçekleştirdikleri hastalarda \%40 oranında instabiliteyle karşılaştıklarını belirtmektedirler. ${ }^{[14]}$ Pillukat ve ark.'nın yaptıkları bir çalışmada ise, travma sonrası DRUE artrozu için uyguladıkları HíA hastalarında ulnada instabilite olmasına rağmen hastaların ağrılarında belirgin azalma olduğunu, kavrama kuwetinde belirgin artış olduğunu ve genel olarak el fonksiyonlarında belirgin düzelme sağladıklarını bildirmişlerdir. ${ }^{[15]}$ Biz de ayrıntılı ve ameliyat öncesi değerlendirmenin ardından konulacak doğru tanıy takiben yapılacak HiA işleminin hastada belirgin fonksiyonel düzelme sağlayacağına inanıyoruz.

\section{KAYNAKLAR}

1. Moore EM. Three cases illustrating luxation of the ulna in connection with Colles' fracture. Med Rec 1880;17:305-8.

2. Darrach W. Anterior dislocation of the head of the ulna. Ann Surg 1912;56(5):802. https://www.ncbi.nlm.nih.gov/pmc/ articles/PMC1407352/?page $=18$

3. Darrach W. Partial excision of lower shaft of the ulna for deformity following Colles' fracture. Ann Surg 1913;57:764-5.

4. Hartz CR, Beckenbaugh RD. Long-term results of resection of the distal ulna for post-traumatic conditions. J Trauma 1979;19(4):219-26. Crossref

5. Lugnegarrd $H$. Resection of the head of the ulna in posttraumatic dysfunction of the distal radioulnar joint. Scand J Plast Reconstr Surg 1969;3:65-9. Crossref

6. Bowers WH. Distal radioulnar joint arthroplasty: the hemiresection-interposition technique. J Hand Surg Am 1985;10(2):169-78. Crossref

7. Watson HK, Ryu JY, Burgess RC. Matched distal ulnar resection. J Hand Surg Am 1986;11(6):812-7. Crossref

8. Minami A, Ogino T, Minami M. Treatment of distal radioulnar disorders. J Hand Surg Am 1987;12(2):189-96. Crossref

9. Minami A, Suzuki K, Suenaga N, Ishikawa J. Hemiresectioninterposition arthroplasty for osteoarthritis of the distal radioulnar joint. Int Orthop 1995;19(1):35-9. Crossref

10. Ruby LK, Ferenz CC, Dell PC. The pronator quadratus interposition transfer: an adjunct to resection arthroplasty of the distal radioulnar joint. J Hand Surg Am 1996;21(1):60-5. Crossref

11. Sauerbier M, Fujita M, Hahn ME, Neale PG, Berger RA. The dynamic radioulnar convergence of the Darrach procedure and the ulnar head hemiresection interposition arthroplasty: a biomechanical study. J Hand Surg Br 2002;27(4):307-16. Crossref

12. del Pino JG, Fernández DL. Salvage procedure for failed Bowers' hemiresection interposition technique in the distal radioulnar joint. J Hand Surg Br 1998;23(6):749-53. Crossref

13. Minami A, Iwasaki N, Ishikawa J, Suenaga N, Yasuda K, Kato $\mathrm{H}$. Treatments of osteoarthritis of the distal radioulnar joint: long-term results of three procedures. Hand Surg 2005;10(23):243-8. Crossref

14. van Schoonhoven J, Kall S, Schober F, Prommersberger KJ, Lanz U. Die Hemiresektions-Interpositionsarthroplastik als Rettungsoperation bei Arthrose des distalen Radioulnargelenkes [The hemiresection-interposition arthroplasty as a salvage procedure for the arthrotically destroyed distal radioulnar joint]. Handchir Mikrochir Plast Chir 2003;35(3):175-80. Crossref

15. Pillukat $T$, van Schoonhoven J. Die HemiresektionsInterpositionsarthroplastik des distalen Radioulnargelenks nach Bowers [The hemiresection-interposition arthroplasty of the distal radioulnar joint]. Oper Orthop Traumatol 2009;21(4-5):484-97. Crossref 